\title{
Vitamin D deficiency as a risk factor for infection, sepsis and mortality in the critically ill: systematic review and meta-analysis
}

\author{
Kim de Haan ${ }^{1 *}, A B$ Johan Groeneveld ${ }^{2}$, Hilde RH de Geus ${ }^{3}$, Mohamud Egal $^{3}$ and Ard Struijs ${ }^{1}$
}

\begin{abstract}
Introduction: In Europe, vitamin D deficiency is highly prevalent varying between $40 \%$ and $60 \%$ in the healthy general adult population. The consequences of vitamin D deficiency for sepsis and outcome in critically ill patients remain controversial. We therefore systematically reviewed observational cohort studies on vitamin D deficiency in the intensive care unit.
\end{abstract}

Methods: Fourteen observational reports published from January 2000 to March 2014, retrieved from Pubmed and Embase, involving 9,715 critically ill patients and serum 25-hydroxyvitamin $\mathrm{D}_{3}(25(\mathrm{OH})$-D) concentrations, were meta-analysed.

Results: Levels of $25(\mathrm{OH})$-D less than $50 \mathrm{nmol} / \mathrm{L}$ were associated with increased rates of infection (risk ratio (RR) 1.49, 95\% (confidence interval (Cl) 1.12 to 1.99), $P=0.007$ ), sepsis (RR 1.46, 95\% (Cl 1.27 to 1.68), $P<0.001$ ), 30-day mortality (RR 1.42, 95\% (Cl 1.00 to 2.02), $P=0.05$ ), and in-hospital mortality (RR $1.79,95 \%$ (Cl 1.49 to 2.16 ), $P<0.001$ ). In a subgroup analysis of adjusted data including vitamin $\mathrm{D}$ deficiency as a risk factor for 30-day mortality the pooled RR was 1.76 (95\% Cl 1.37 to $2.26, P<0.001)$.

Conclusions: This meta-analysis suggests that vitamin D deficiency increases susceptibility for severe infections and mortality of the critically ill.

\section{Introduction}

Vitamin D deficiency, defined as serum 25-hydroxyvitamin $\mathrm{D}_{3}(25(\mathrm{OH})-\mathrm{D})$ concentrations below $50 \mathrm{nmol} / \mathrm{L}$, is highly prevalent in Dutch critically ill patients [1]. Several studies in critically ill patients report associations between vitamin D deficiency, a disturbed parathyroid hormone (PTH)-vitamin $\mathrm{D}$ axis and increased mortality [2-5]. A biological basis how hypovitaminosis $\mathrm{D}$ may cause mortality could be hypocalcaemia. Hypocalcaemia is a well-known abnormality in critically ill patients in the course of sepsis and rhabdomyolysis [6]. Second, vitamin D regulates both innate and adaptive immune systems. Vitamin D deficiency leads to immune dysregulation and has been proposed as an underlying pathogenic mechanism of infections [7]. Third, vitamin D deficiency is associated with increased markers of systemic inflammation associated with multi-

\footnotetext{
* Correspondence: k.dehaan@erasmusmc.nl

'Department of Intensive Care, Erasmus Medical Centre, Mailbox 2040,

H603a, 3000CA Rotterdam, The Netherlands

Full list of author information is available at the end of the article
}

organ failure [8]. Moreover hypovitaminosis D reduces, despite maximal upregulation of PTH levels, formation of 1,25-dihydroxyvitamin $\mathrm{D}_{3}(1,25(\mathrm{OH})-\mathrm{D})$ at the tissue level. This may be critical in mediating the beneficial pleiotropic functions of vitamin D, involving innate immunity, mucosal barrier and endothelial function. Recently, a systematic review and meta-analysis including observational and interventional studies on vitamin D in non-critically ill patients, suggests an association of deficiency with cardiovascular diseases, diabetes, and all-cause mortality in the former but not in the latter studies [9]. In non-critically ill patients, of a prior meta-analysis of 18 randomised controlled trials, intake of supplementary doses of vitamin D was associated with a $7 \%$ decrease in mortality [10].

Therefore, we conducted a systematic review to pool the available data and to study the possible effect of vitamin D deficiency in critically ill patients on the incidence of infection, sepsis and association with mortality. 


\section{Materials and methods Search strategy}

The report of this protocol-driven systematic review and meta-analysis follows the Preferred Reporting Items for Systematic reviews and Meta-Analyses (PRISMA) and Meta-analysis Of Observational Studies in Epidemiology guidelines (MOOSE) [11]. A Medline, Embase and Cochrane Library search was conducted with the help of biomedical information specialists, limited to publications from January 2000 until March 2014 in humans. The search consisted of two terms: vitamin D and intensive care. The controlled thesaurus terms we used for vitamin $\mathrm{D}$ were vitamin $\mathrm{D}$ and vitamin $\mathrm{D}$ deficiency. The concept intensive care was covered by the following keywords: intensive care unit (ICU), intensive care nursing, critical care and critically ill patients. For Medical Subject Heading (MeSH) terms and search strategy see S1 Table 1 in Additional file 1. References of included articles were cross-checked for other relevant studies. One author [12] was successfully contacted twice because not all required information could be retrieved from the publication.

\section{Study selection}

Two independent authors, a researcher $(\mathrm{KdH})$ and an intensivist (AS) screened titles and abstracts for eligibility. In case of disagreement, agreement of a third author (ME) provided a final option. Studies eligible for inclusion in the systematic review were observational studies describing ICU patients, reporting on serum $25(\mathrm{OH})$-D concentrations, outcomes, and those written in English. Studies in which participants were younger than 18 years, sample size was less than 20 patients and participants suffered from parathyroid disease, human immunodeficiency virus infection and end-stage renal disease requiring chronic dialysis were excluded. Abstracts, letters, reviews and conference articles were excluded as well.

\section{Definitions}

In this meta-analysis vitamin $\mathrm{D}$ deficiency was $a$ priori defined as a reported serum concentration $<50 \mathrm{nmol} / \mathrm{L}$, as advocated by the American Institute of Medicine [13]. However, the included studies unfortunately reported a wide range of cutoffs for vitamin D deficiency. Prior to analysing the data for each study, agreement was negotiated between two authors, $\mathrm{KdH}$ and $\mathrm{AS}$, which vitamin D cutoffs to be used in the meta-analysis, see Table 1 . Due to the designed search strategy, there was no clear definition of infection and sepsis between included studies. The reported occurrence of infections comprised any kind of infections such as pneumonia, urinary tract, bacteraemia and intraabdominal infections. The included studies defined sepsis varying from having positive blood cultures or systemic inflammatory response syndrome (SIRS) criteria combined with a source of infection. We reported the complete overview of definitions used in S2 Table 2 in Additional file 1. Mortality rates were extracted as in-hospital and 30-day mortality. Thirty-day mortality rates are well described and defined in the included articles. All other definitions of mortality, like ICU mortality, in-hospital mortality, acute inhospital mortality, were taken together as in-hospital mortality. When articles separately reported ICU and in-hospital mortality, we combined numbers together in the analysis as in-hospital mortality.

\section{Statistical analysis}

Review Manager (version 5.2 for Windows, The Cochrane Collaboration, 2011) was used for the analysis. Occurrence of infections, sepsis and mortality, as defined in the studies, was calculated for each individual study and the estimated risk ratios (RRs) were pooled comparing the effect of deficient levels (sufficient levels as reference) of 25 (OH)-D with the use of the inverse variance (IV) method in a random-effects model, yielding RRs and 95\% confidence intervals (CIs). The IV method was used because of the assumption that less variance in a study should contribute to its weight in significance. A random-effects model was used due to expected heterogeneity between studies. If raw data was not available to calculate the RRs, we used the reported odds ratios (ORs) and converted the reported ORs to RRs with corresponding 95\% CIs. Otherwise, we manually calculated the RRs from the available data. Additionally, taking confounding into account, we decided to perform a subgroup analysis of adjusted data reported on 30-day mortality. Unfortunately, most studies do not report adjusted data on infections, sepsis and inhospital mortality, so we were not able to make a subgroup analysis of those. Subgroup analyses were performed to examine the difference per outcome based on study design. To determine publication bias we used funnel plots (Figures S3-S7 in Additional file 1). Heterogeneity was assessed with the use of the Cochran Q statistics and the $\mathrm{I}^{2}$ test. We used the Newcastle-Ottawa scale to evaluate the quality of included studies. This scale uses a star system (with a maximum of nine stars) to evaluate a study in three domains: selection of participants, comparability of study groups, and the ascertainment of outcomes of interest. We judged studies that received a score of nine or eight stars to be at low risk of bias, studies that scored seven or six stars to be at medium risk, and scores below six to be at high risk of bias (S8a,b in Additional file 1).

\section{Results}

\section{Search strategy}

A total of 381 studies were screened; 358 were excluded for the following reasons: irrelevant $(n=229)$, review $(n=7)$, study design or too small in sample size $(n=26)$, only focused on vitamin D metabolism $(n=45)$, pediatric studies 
Table 1 Overview of publications used in the meta-analysis

\begin{tabular}{|c|c|c|c|c|c|c|c|}
\hline Author & $\begin{array}{l}\text { Year of } \\
\text { publication }\end{array}$ & Study population & Study design & Number of patients & Endpoints & $\begin{array}{l}\text { Comparison } \\
\text { (in meta-analysis) }\end{array}$ & $\begin{array}{l}\text { Study* } \\
\text { quality }\end{array}$ \\
\hline Amrein et al. [25] & 2014 & Medical, surgical ICU & Retrospective, cohort & 655 & Sepsis, in-hospital mortality & $<50 \mathrm{nmol} / \mathrm{l}$ vs $>75 \mathrm{nmol} / \mathrm{l}$ & 7 \\
\hline Arnson et al. [21] & 2012 & Medical, surgical ICU & Prospective, cohort & 130 & Infections & $\leq 50 \mathrm{nmol} / \mathrm{l}$ vs $>50 \mathrm{nmol} / \mathrm{l}$ & 6 \\
\hline Aygencel et al. [24] & 2013 & Medical ICU & Prospective, cohort & 201 & Infections, sepsis, in-hospital mortality & $<50 \mathrm{nmol} / \mathrm{l}$ vs $\geq 50 \mathrm{nmol} / \mathrm{l}$ & 4 \\
\hline Braun et al. [5] & 2012 & Medical, surgical ICU & Two-centre, retrospective, cohort & 1,325 & Sepsis, 30-day, in-hospital mortality & $\leq 37 \mathrm{nmol} / \mathrm{l}$ vs $\geq 75 \mathrm{nmol} / \mathrm{l}$ & 8 \\
\hline Braun et al. [3] & 2011 & Surgical ICU & Two-centre, retrospective, cohort & 2,399 & Infections, 30-day, in-hospital mortality & $\leq 37 \mathrm{nmol} / \mathrm{l}$ vs $\geq 75 \mathrm{nmol} / \mathrm{l}$ & 8 \\
\hline Flynn et al. [22] & 2012 & Medical, surgical ICU & Prospective, cohort & 66 & Infections, sepsis, in-hospital mortality & $\leq 50 \mathrm{nmol} / \mathrm{l}$ vs $>50 \mathrm{nmol} / \mathrm{l}$ & 2 \\
\hline Higgins et al. [23] & 2012 & Medical, surgical ICU & Prospective, cohort & 196 & Infections, sepsis, 30-day mortality & $\leq 30 \mathrm{nmol} / \mathrm{l}$ vs $\geq 60 \mathrm{nmol} / \mathrm{l}$ & 7 \\
\hline Lucidarme et al. [12] & 2012 & Medical, surgical ICU & Prospective, cohort & 134 & 30-day mortality & $>15-\leq 30$ vs $\geq 60 \mathrm{nmol} / \mathrm{l}$ & 5 \\
\hline Matthews et al. [30] & 2012 & Medical ICU & Prospective, cohort & 258 & In-hospital mortality & $\geq 10-\leq 32$ vs $67-97 \mathrm{nmol} / \mathrm{l}$ & 3 \\
\hline Moromizato et al. [26] & 2014 & Medical, surgical ICU & Two-centre, retrospective, cohort & 3,386 & Sepsis & $\leq 37 \mathrm{nmol} / \mathrm{l}$ vs $\geq 75 \mathrm{nmol} / \mathrm{l}$ & 8 \\
\hline Nair et al. [27] & 2012 & Medical ICU & Prospective, cohort & 100 & 30-day-, in-hospital mortality & $<25 \mathrm{nmol} / \mathrm{l}$ vs $\geq 50 \mathrm{nmol} / \mathrm{l}$ & 6 \\
\hline Remmelts et al. [28] & 2012 & Ward, medical ICU & Prospective, cohort & 272 & 30-day mortality & $\leq 50 \mathrm{nmol} / \mathrm{l}$ vs $\geq 75 \mathrm{nmol} / \mathrm{l}$ & 7 \\
\hline Su et al. [29] & 2013 & Medical, surgical ICU & Prospective, cohort & 156 & 30-day mortality & $\leq 37 \mathrm{nmol} / \mathrm{l}$ vs $\geq 75 \mathrm{nmol} / \mathrm{l}$ & 6 \\
\hline Venkatram et al. [4] & 2011 & Medical ICU & Retrospective, cohort & 437 & Sepsis, in-hospital mortality & $\leq 50 \mathrm{nmol} / \mathrm{l}$ vs $\geq 75 \mathrm{nmol} / \mathrm{l}$ & 4 \\
\hline
\end{tabular}

"Study quality assessed by the Newcastle-Ottawa scale, see S8 in Additional file 1. ICU, intensive care unit. 
( $\mathrm{n}=46)$ and animal studies ( $\mathrm{n}=5)$, after detailed evaluation, one additional study was excluded because of duplicates. All studies included in this analysis $(\mathrm{n}=14)$ were prospective cohort studies $(n=9)$ or had retrospective designs $(n=5)$. We were not able to include all studies because they described different outcomes like effect on delirium, antimicrobial peptide levels and 90-day mortality $[8,14,15]$ or their results [16] were not formatted to allow combining the results with the other studies. We also excluded four interventional trials because they were small in sample size and none reported on infections, sepsis and mortality [17-20], (S9 Figure 1 in Additional file 1).

\section{Study characteristics}

Fourteen observational reports published from January 2000 until March 2014 involving 9,715 critically ill patients were included. The average serum $25(\mathrm{OH})-\mathrm{D}$ level of the study population was $45 \mathrm{nmol} / \mathrm{L}$. Mean age was 62 years and the majority of the patients, 53\%, were male. The presence of infections was $31 \%$ and sepsis occurred in $28 \%$ of the patients. The average 30 -day mortality in this study cohort was $17.5 \%$ and the in-hospital mortality rate $18.4 \%$. Characteristics of the studies are presented in Table 1. For a complete overview of study characteristics of studies included in the meta-analysis see S2 Table 2 in Additional file 1.

\section{$25(\mathrm{OH})-\mathrm{D}$ levels and infections}

Five [3,21-24] of the fourteen studies reported on infections. We pooled the manually calculated RRs for the effect of low levels of $25(\mathrm{OH})-\mathrm{D}$ on infections (Figure 1), including 1,967 patients. The pooled RR was 1.49 (95\% CI 1.12 to 1.99$)$.

\section{5 (OH)-D levels and sepsis}

The RRs in seven $[4,5,22-26]$ of the fourteen studies were manually calculated, involving 3,844 patients (Figure 2). The pooled RR was 1.46 (95\% CI 1.27 to 1.68).

\section{$25(\mathrm{OH})$-D levels and mortality}

Seven of the fourteen studies reported on 30-day mortality, with ORs either available in the articles converted to RRs $[3,5] \quad(\mathrm{n}=2)$ or manually calculated RRs [12,23,27-29] $(\mathrm{n}=5)$, involving 2,857 patients (Figure 3 ). The pooled $R R$ was 1.42 (95\% CI 1.00 to 2.02). Two studies [3,5] used a multivariate model adjusted for age, gender, race, disease severity, season and ICU type. Remmelts et al. [28] adjusted for age and heart failure in the multivariate analysis and Nair et al. [27] for age and disease severity. The pooled subgroup analysis of adjusted data involving 2,572 patients demonstrated an increased RR for 30-day mortality associated with vitamin D deficiency by 1.76 (95\% CI 1.37 to 2.26) (Figure 4). Eight $[3-5,22,24,25,27,30]$ of the fourteen studies reported in-hospital mortality of 3,606 patients (Figure 5). The pooled RR was 1.79 (95\% CI 1.49 to 2.16).

\section{Subgroup analyses per outcome based on study design}

The effect on outcome in prospective study data is lower than in retrospective data see S10 in Additional file 1, but there were less prospective data.

\section{Discussion}

This study represents the first comprehensive systematic review and meta-analysis focused on studies in which the effects of vitamin D deficiency in critically ill patients on occurrence of infection, sepsis and mortality rates are described. These results show that vitamin $\mathrm{D}$ deficiency $(<50 \mathrm{nmol} / \mathrm{L})$ is associated with increase in

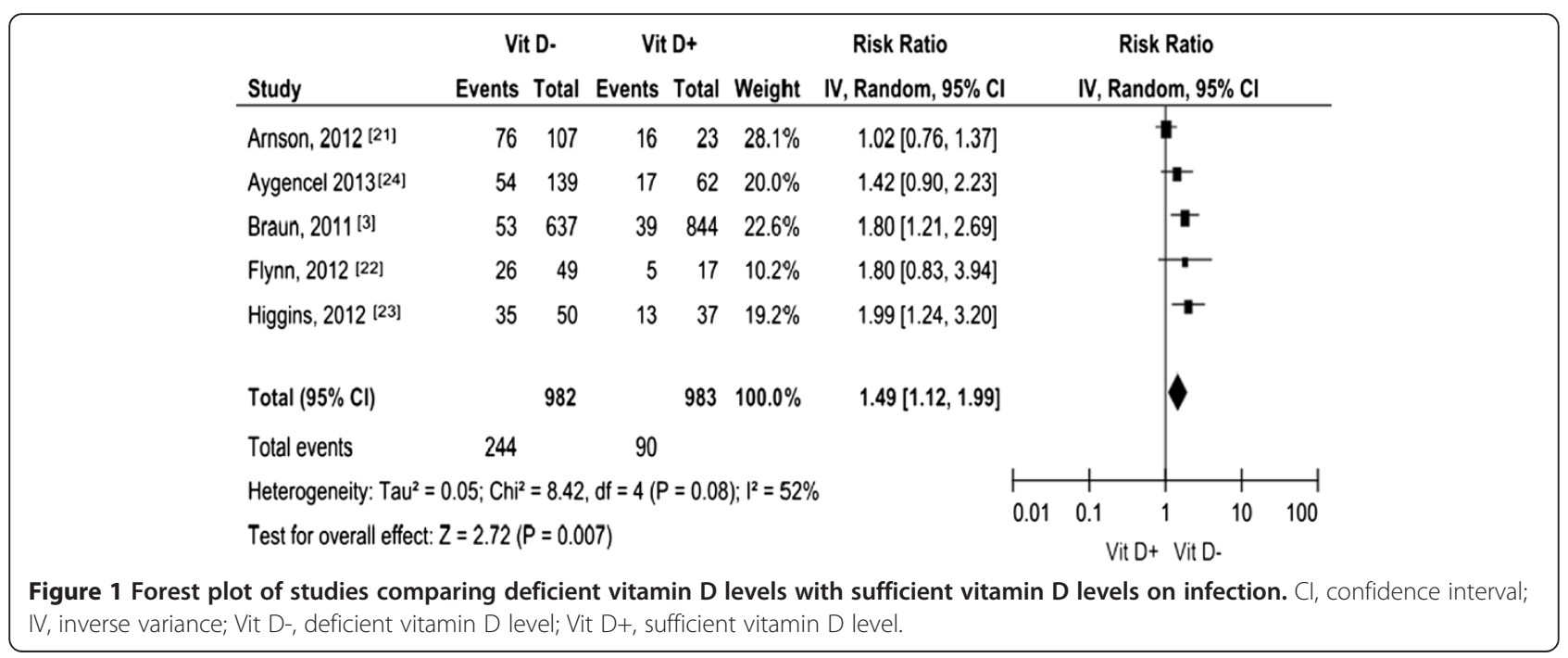




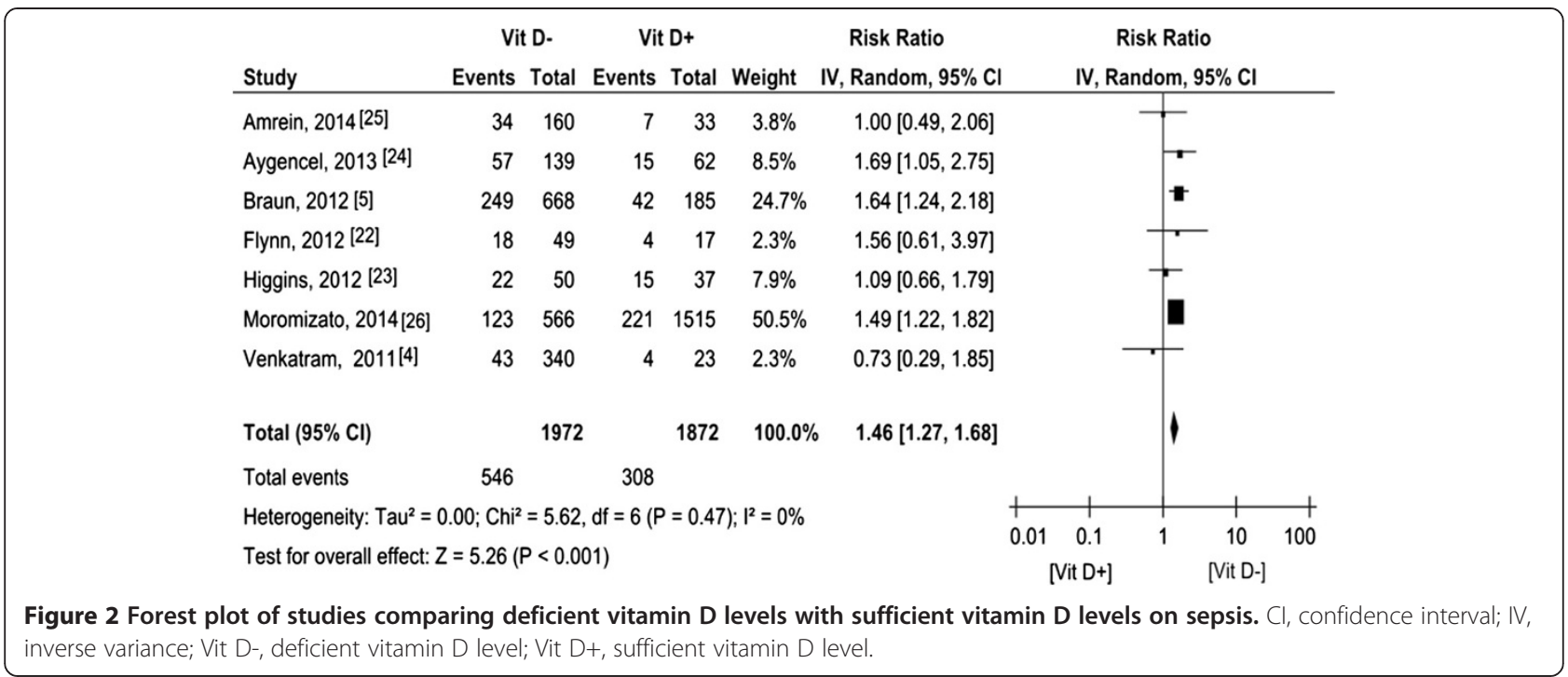

infection rate, sepsis, 30-day mortality and in-hospital mortality in adult critically ill patients, worldwide.

The association between vitamin D status and immunity has been already supported by a number of studies [31-33]. However, results in healthy volunteers exposed to experimental human endotoxaemia suggest a lack of this association between vitamin $\mathrm{D}$ and inflammatory cytokine levels [34]. Therefore, it is suggested that the differences in the ability to produce vitamin $\mathrm{D}$, may contribute to a difference in the susceptibility to microbial infection. Our study adds to the discussion on the association by an objectively derived pooled risk. The relation between 25 $(\mathrm{OH})-\mathrm{D}$ levels and sepsis has been described previously [8]. Vitamin D-deficient patients are at higher risk for blood culture positivity, which may contribute to higher sepsis rates [3]. However, Cecchi et al. found no clear relationship on outcome between lower vitamin D levels in septic patients when compared with a matched cohort [16]. The most recent study by Moromizato et al. included in our analysis specifically showed a threshold of $25(\mathrm{OH})$ -
D less than or equal to $40 \mathrm{nmol} / \mathrm{L}$ to be associated with sepsis [26]. Thus our results are in agreement with the hypothesis that vitamin $\mathrm{D}$ deficiency is a contributor to sepsis.

Some published studies $[17,35]$ suggested an association between vitamin $\mathrm{D}$ deficiency and mortality in critically ill patients. In the study by Van den Berghe et al. both 25 $(\mathrm{OH})-\mathrm{D}$ and 1,25 $(\mathrm{OH})-\mathrm{D}$ levels were lower among nonsurvivors in critically ill patients [17]. Matthews et al. noted in their surgical ICU cohort that most deaths occurred at vitamin D levels less than $32 \mathrm{nmol} / \mathrm{L}$ and that no deaths occurred at levels higher than $65 \mathrm{nmol} / \mathrm{L}$ [30]. The CopD study done by Durup et al. reported a reversed J-shape relation between $25(\mathrm{OH})-\mathrm{D}$ and all-cause mortality, suggesting that too much and too little are deleterious. A serum 25 $(\mathrm{OH})-\mathrm{D}$ of 50 to $60 \mathrm{nmol} / \mathrm{L}$ was associated with the lowest mortality risk [36]. The results of this meta-analysis suggest that vitamin $\mathrm{D}$ levels below $50 \mathrm{nmol} / \mathrm{L}$, increase 30-day mortality and in-hospital mortality with $76 \%$ and $79 \%$ respectively. To date, only four randomised trials in adult

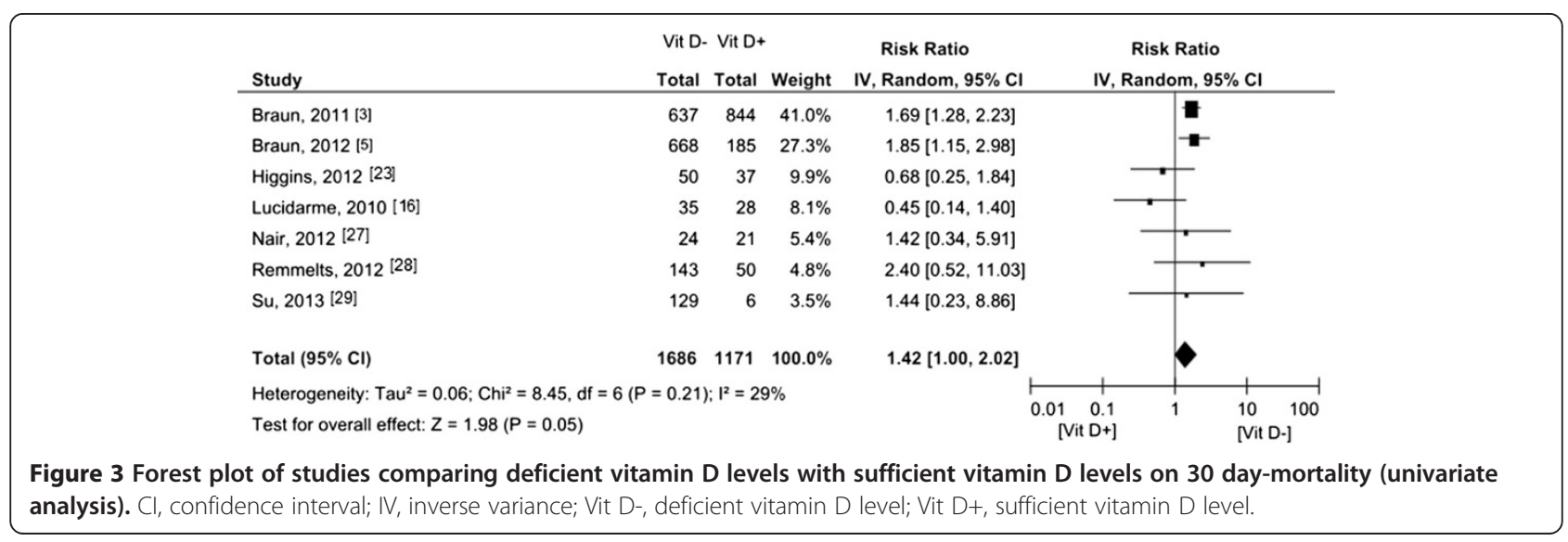




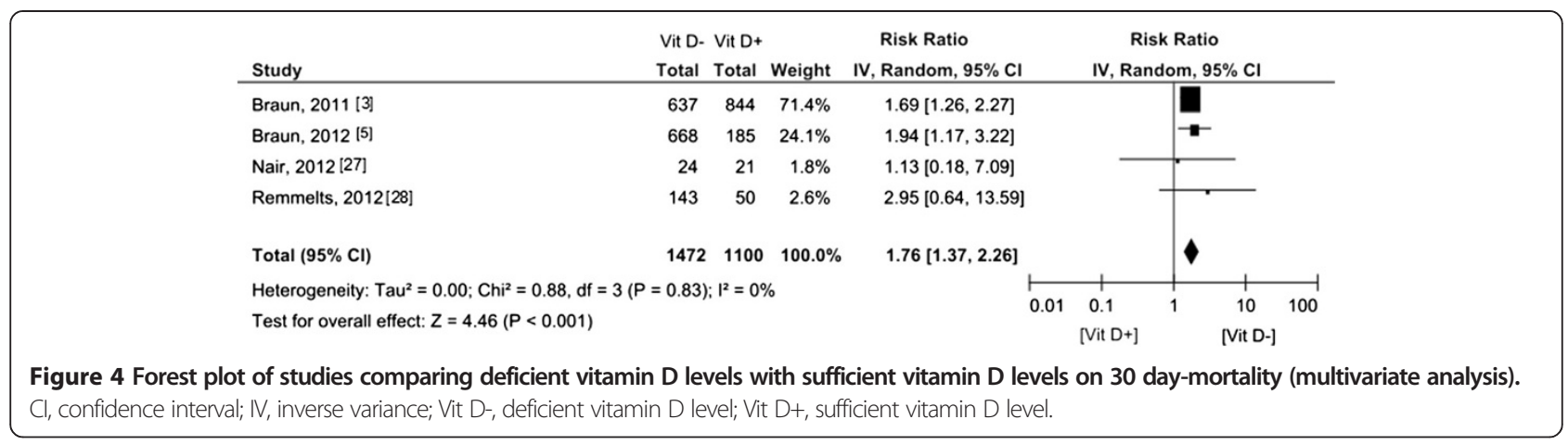

critically ill patients have been published, which were designed to study normalisation of vitamin D levels and its possible adverse effects such as hypercalcaemia and hypercalciuria [17-20]. These studies were not sufficiently powered to investigate the effects of vitamin D normalisation and potential benefits on hard outcomes such as incidence of severe infections and/or ICU mortality (S11 Table 3 in Additional file 1). The recently published Lancet review supports the relation between $25(\mathrm{OH})$-D deficiency and all-cause mortality in observational studies [9]. The discrepancy with the interventional studies could be due to underpowered numbers, low dosages or short duration of supplementation. The role for supplementation is unclear and appropriate dose-response studies with 1,25 and 25 $(\mathrm{OH})-\mathrm{D}$ must be done. Therefore the authors conclusion about low vitamin D as merely a marker of disease has to be confirmed in prospective interventional studies.

Data from biochemical and molecular studies indicate that vitamin $\mathrm{D}$, in particular its active form 1,25 (OH)-D, has a much wider role than only the maintenance of calcium homeostasis and bone health. Sufficiency of vitamin $\mathrm{D}$ activity can thus also be defined by sufficient autocrine and paracrine production of $1,25(\mathrm{OH})-\mathrm{D}$ at serum $25(\mathrm{OH})-\mathrm{D}$ levels of at least around $75 \mathrm{nmol} / \mathrm{L}$ $[37,38]$. This active form is responsible for most, if not all, of the biological and pleiotropic effects including antimicrobial actions and immunomodulatory effects of vitamin $\mathrm{D}[7,39]$. The study by Zittermann et al. demonstrated the superiority of predicting mortality by 1,25 $(\mathrm{OH})-\mathrm{D}$ as compared to $25(\mathrm{OH})-\mathrm{D}$, supporting the assumption that adequately circulating 1,25 (OH)-D levels may play a role for survival [40]. Marshall et al. emphasised measuring 1,25 (OH)-D instead of total $25(\mathrm{OH})-\mathrm{D}$ as well; they postulated that the disease processes regulate vitamin D metabolism so that the low $25(\mathrm{OH})-\mathrm{D}$ levels observed in disease may be merely a biomarker of disease severity [39]. Unfortunately, the observational articles meta-analysed in this manuscript do not consider $1,25(\mathrm{OH})$-D on outcomes.

Two studies [3,5] had a time lag between admission into the ICU and vitamin D blood sampling. To illustrate the importance between $25(\mathrm{OH})$-D time of measurement and admission, the authors conducted a sensitivity analysis considering patients with $25(\mathrm{OH})$-D drawn before or after 90 days prior to hospital admission. This sensitivity analysis showed that the association that was found between vitamin D on outcomes was not modified by time lag.

Our study has several limitations. First, we included both prospective and retrospective studies in this meta-analysis, which is a matter of debate. In retrospective studies the

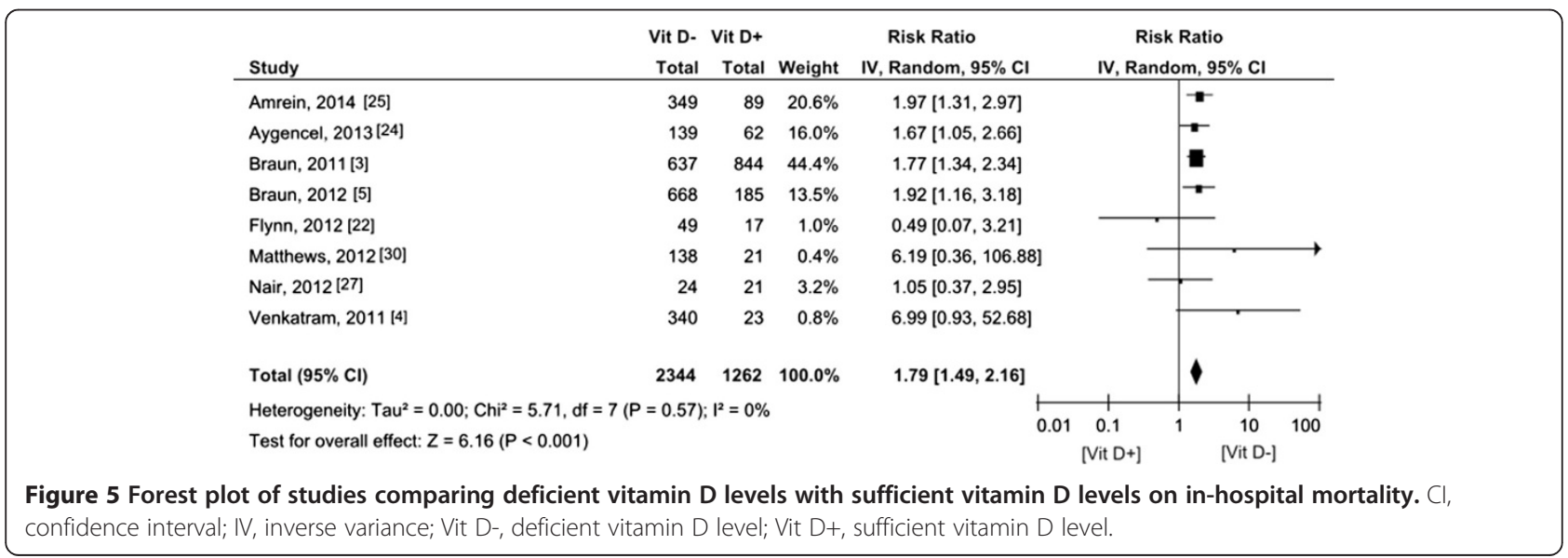


control for confounders is difficult. We have addressed this by adding a subgroup analyses per outcome based on design, see S10 in Additional file 1. However, in the prospective study data the effect on mortality is lower, whereas the sample size in the prospective studies may have been insufficient to show an association. The five retrospective papers $[3-5,25,26]$ contain large sample sizes enabling multivariate analysis for mortality ruling out confounders such as age, gender, race, glomerular filtration rate (GFR), C-reactive protein (CRP), season, disease severity and so on. Second, the studies included are observational so that a causative link between hypovitaminosis D and outcomes cannot be established. Additionally, the variability in measured $25(\mathrm{OH})$-D levels is probably multifactorial. It is possible that a random single $25(\mathrm{OH})$ D measurement in ICU patients does not appropriately reflect the vitamin D status [41]. Furthermore, alterations in vitamin D binding protein, fluid shifts [42] and assay variability with coefficients of variation ranging from $6 \%$ to $13 \%$ [43] may limit applicability of single measurements on outcome prediction used in most of the included studies. The different cutoff levels used by different studies are based on study endpoints (for example, fracture or osteoporosis) done in the general population. The applicability of these cutoff levels in the critically ill is unclear, especially because cutoff values between bone- specific and pleiotropic endpoints are different. There is heterogeneity in the definitions of infection and sepsis used in the included studies, sepsis was defined varying from positive blood cultures [3] to SIRS criteria together with a source of infection [23] but the $\mathrm{I}^{2}$ test did not show heterogeneity. We only found some heterogeneity $(P=0.08)$ in the forest plot combining studies with infection as outcome.

\section{Conclusions}

In conclusion, this is the first meta-analysis suggesting an association between vitamin D deficiency and infection and mortality in the critically ill. This information may help to design placebo-controlled randomised clinical trials on vitamin $\mathrm{D}$ supplementation in preventing severe infections and death in the ICU.

\section{Key messages}

- $25(\mathrm{OH})-\mathrm{D}$ deficiency is highly prevalent across intensive care population worldwide.

- In critically ill patients, $25(\mathrm{OH})$-D deficiency is associated with mortality.

- $25(\mathrm{OH})-\mathrm{D}$ deficiency may be a risk factor for infections and sepsis.

- We support the need for adequately powered prospective, dose-response trials to evaluate the effect of vitamin D substitution on infection rates, sepsis and mortality in the critically ill.

\section{Additional file}

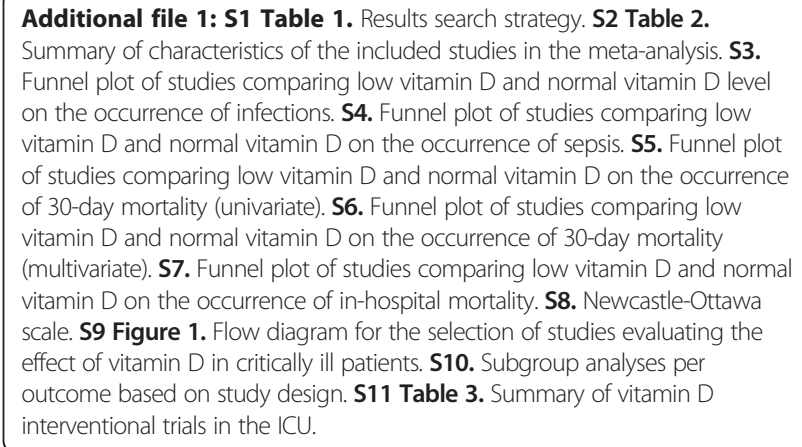

\section{Abbreviations}

1,25 (OH)-D: 1,25-dihydroxyvitamin $\mathrm{D}_{3} ; 25(\mathrm{OH})$-D: 25-hydroxyvitamin $\mathrm{D}_{3}$; Cl: confidence interval; CRP: C-reactive protein; GFR: glomerular filtration rate; ICU: intensive care unit; IV: inverse variance; MeSh: Medical Subject Heading; MOOSE: Meta-Analysis Of Observational Studies in Epidemiology guidelines; OR: odds ratio; PRISMA: Preferred Reporting Items for Systematic reviews and Meta-Analyses; PTH: parathyroid hormone; RR: risk ratio; SIRS: systemic inflammatory response syndrome.

\section{Competing interests}

The authors declare they have no competing interests. None of the authors received financial support for this study.

\section{Authors contributions}

$\mathrm{KdH}, \mathrm{ABJG}$ and $\mathrm{AS}$ designed the study; $\mathrm{KdH}$ and ME performed the meta-analysis. $\mathrm{KdH}$ prepared the manuscript. ABJG supervised, and AS and HRHG edited the manuscript. All authors read and approved the final manuscript.

\section{Author details}

'Department of Intensive Care, Erasmus Medical Centre, Mailbox 2040, H603a, 3000CA Rotterdam, The Netherlands. '2Department of Intensive Care, Erasmus Medical Centre, Mailbox 2040, H603, 3000CA Rotterdam, The Netherlands. ${ }^{3}$ Department of Intensive Care, Erasmus Medical Centre, Mailbox 2040, H619, 3000CA Rotterdam, The Netherlands.

Received: 26 June 2014 Accepted: 12 November 2014

Published online: 05 December 2014

\section{References}

1. Weenink JJ, Oudemans-Van Straaten H, Yap HT, Slaats EH, Van Der Voort PH: High prevalence of severe vitamin D deficiency in intensive care patients. Crit Care 2010, 14:S198.

2. Lee $P$, Nair $P$, Eisman JA, Center JR: Vitamin D deficiency in the intensive care unit: an invisible accomplice to morbidity and mortality? Intensive Care Med 2009, 35:2028 2032.

3. Braun A, Chang D, Mahadevappa K, Gibbons FK, Liu Y, Giovannucci E, Christopher KB: Association of low serum 25-hydroxyvitamin D levels and mortality in the critically ill. Crit Care Med 2011, 39:671 677.

4. Venkatram S, Chilimuri S, Adrish M, Salako A, Patel M, Diaz-Fuentes G: Vitamin $D$ deficiency is associated with mortality in the medical intensive care unit. Crit Care 2011, 15:R292.

5. Braun AB, Gibbons FK, Litonjua AA, Giovannucci E, Christopher KB: Low serum 25-hydroxyvitamin $D$ at critical care initiation is associated with increased mortality. Crit Care Med 2012, 40:63 72.

6. Zaloga GP, Chernow B: Hypocalcemia in critical illness. JAMA 1986, 256(14):1924 1929.

7. Hewison M, Zehnder D, Chakraverty R, Adams JS: Vitamin D and barrier function: a novel role for extra-renal 1 alpha-hydroxylase. Mol Cell Endocrinol 2004, 215:31 38.

8. Jeng L, Yamshchikov AV, Judd SE, Blumberg HM, Martin GS, Ziegler TR, Tangpricha $V$ : Alterations in vitamin D status and anti-microbial peptide levels in patients in the intensive care unit with sepsis. J Transl Med 2009, 7:28. 
9. Autier P, Boniol M, Pizot C, Mullie P: Vitamin D status and ill health: a systematic review. Lancet Diabetes Endocrinol 2014, 2:76 89.

10. Autier P, Gandini S: Vitamin D supplementation and total mortality: a meta-analysis of randomized controlled trials. Arch Intern Med 2007 167:1730 1737.

11. Stroup DF, Berlin JA, Morton SC, Olkin I, Williamson GD, Rennie D, Moher D, Becker BJ, Sipe TA, Thacker SB: Meta-analysis of observational studies in epidemiology: a proposal for reporting. Meta-analysis Of Observational Studies in Epidemiology (MOOSE) group. JAMA 2000, 283:2008 2012

12. Lucidarme O, Messai E, Mazzoni T, Arcade M, Du Cheyron D: Incidence and risk factors of vitamin $D$ deficiency in critically ill patients: Results from a prospective observational study. Intensive Care Med 2010, 36:1609 1611.

13. Ross AC, Manson JE, Abrams SA, Aloia JF, Brannon PM, Clinton SK, Durazo-Arvizu RA, Gallagher JC, Gallo RL, Jones G, Kovacs CS, Magne ST, Rosen CI, Shapes SA: The 2011 report on dietary reference intakes for calcium and vitamin D from the Institute of Medicine: what clinicians need to know. J Clin Endocrinol Metab 2011, 96:53 58

14. Morandi A, Barnett N, Miller RR, Girard TD, Pandharipande PP, Ely EW, Ware LB: Vitamin D and delirium in critically ill patients: a preliminary investigation. J Crit Care 2012, 28:230 235.

15. Quraishi SA, Bittner EA, Blum L, McCarthy CM, Bhan I, Camargo CA Jr: Prospective study of vitamin D status at initiation of care in critically ill surgical patients and risk of 90-day mortality. Crit Care Med 2014, 42:1365 1371

16. Cecchi A, Bonizzoli M, Douar S, Mangini M, Paladini S, Gazzini B, Degl'innocenti S, Linden M, Zagli G, Peris A: Vitamin D deficiency in septic patients at ICU admission is not a mortality predictor. Minerva Anestesiol 2011, 77:1184 1189.

17. Van Den Berghe G, Van Roosbroeck D, Vanhove P, Wouters PJ, De Pourcq L, Bouillon R: Bone turnover in prolonged critical illness: effect of vitamin D. J Clin Endocrinol Metab 2003, 88:4623 4632.

18. Mata-Granados JM, Vargas-Vasserot J, Ferreiro-Vera C, de Castro MD L, Pavon RG, Quesada Gomez JM: Evaluation of vitamin D endocrine system (VDES) status and response to treatment of patients in intensive care units (ICUs) using an on-line SPE-LC-MS/MS method. J Steroid Biochem Mol Biol 2010, 121:452 455

19. Amrein K, Sourij H, Wagner G, Holl A, Pieber TR, Smolle KH, Stojakovic T, Schnedl C, Dobnig H: Short-term effects of high-dose oral vitamin D3 in critically ill vitamin D deficient patients: a randomized, double-blind, placebo-controlled pilot study. Crit Care 2011, 15:R104.

20. Vargas-Vasserot J, Mata-Granados JM, Luque De Castro M, Guerrero Pavon R, Quesada Gomez J: 25-hydroxyvitamin D3 treatment normalize the vitamin $D$ status and the innate immune response mediated by cathelicidin in critically ill patients. Bone 2011, 48:S146 S147.

21. Arnson $Y$, Gringauz I, Itzhaky D, Amital $H$ : Vitamin D deficiency is associated with poor outcomes and increased mortality in severely ill patients. QJM 2012, 105:633 639.

22. Flynn L, Zimmerman LH, McNorton K, Dolman M, Tyburski J, Baylor A, Wilson R, Dolman H: Effects of vitamin D deficiency in critically ill surgical patients. Am J Surg 2012, 203:379 382.

23. Higgins DM, Wischmeyer PE, Queensland KM, Sillau SH, Sufit AJ, Heyland DK: Relationship of vitamin D deficiency to clinical outcomes in critically ill patients. J Parenter Enter Nutr 2012, 36:713 720.

24. Aygencel G, Turkoglu M, Tuncel AF, Candir BA, Bildaci YD, Pasaoglu H: Is vitamin $D$ insufficiency associated with mortality of critically ill patients? Crit Care Res Pract 2013, 2013:856747.

25. Amrein K, Zajic P, Schnedl C, Waltensdorfer A, Fruhwald S, Holl A, Urbanic Purkart T, Wunsch G, Valentin T, Grisold A, Stojakovic T, Amrein S, Pieber TR, Dobnig $\mathrm{H}$ : Vitamin D status and its association with season, hospital and sepsis mortality in critical illness. Crit Care 2014, 18:R47.

26. Moromizato T, Litonjua AA, Braun AB, Gibbons FK, Giovannucci E, Christopher KB: Association of low serum 25-hydroxyvitamin D levels and sepsis in the critically ill. Crit Care Med 2014, 42:97 107.

27. Nair $\mathrm{P}$, Lee $\mathrm{P}$, Reynolds C, Nguyen ND, Myburgh J, Eisman JA, Center JR: Significant perturbation of vitamin D-parathyroid-calcium axis and adverse clinical outcomes in critically ill patients. Intensive Care Med 2013, 39:267 274

28. Remmelts HHF, Van De Garde EMW, Meijvis SCA, Peelen ELGCA Damoiseaux JGMC, Grutters JC, Biesma DH, Bos WJW, Rijkers GT: Addition of Vitamin D status to prognostic scores improves the prediction of outcome in community-acquired pneumonia. Clin Infect Dis 2012, 55:1488 1494

29. Su LX, Jiang ZX, Cao LC, Xiao K, Song JP, Li H, Zhang X, Yan P, Feng D, Liu CT, Li X, Xie LX: Significance of low serum vitamin D for infection risk, disease severity and mortality in critically ill patients. Chin Med J (Engl) 2013, 126:2725 2730.

30. Matthews LR, Ahmed Y, Wilson KL, Griggs DD, Danner OK: Worsening severity of vitamin $D$ deficiency is associated with increased length of stay, surgical intensive care unit cost, and mortality rate in surgical intensive care unit patients. Am J Surg 2012, 204:37 43.

31. Liu PT, Stenger S, Li H, Wenzel L, Tan BH, Krutzik SR, Ochoa MT, Schauber J, Wu K, Meinken C, Kamen DL, Wagner M, Bals R, Steinmeyer A, Zugel U, Gallo RL, Eisenberg O, Hewison M, Hollis BW, Adams JS, Bloom BR, Modlin $\mathrm{RL}$ : Toll-like receptor triggering of a vitamin D-mediated human antimicrobial response. Science 2006, 311:1770 1773.

32. Khoo AL, Chai LY, Koenen HJ, Kullberg BJ, Joosten I, van der Ven AJ, Netea MG: 1,25-dihydroxyvitamin D3 modulates cytokine production induced by Candida albicans: impact of seasonal variation of immune responses. J Infect Dis 2011, 203:122 130.

33. Di Rosa M, Malaguarnera M, Nicoletti F, Malaguarnera L: Vitamin D3: a helpful immuno-modulator. Immunology 2011, 134:123 139.

34. Kox M, van den Berg MJ, van der Hoeven JG, Wielders JP, van der Ven AJ, Pickkers P: Vitamin D status is not associated with inflammatory cytokine levels during experimental human endotoxaemia. Clin Exp Immunol 2013, 171:231 236.

35. McKinney JD, Bailey BA, Garrett LH, Peiris P, Manning T, Peiris AN: Relationship between vitamin D status and ICU outcomes in veterans. J Am Med Dir Assoc 2011, 12:208 211.

36. Durup D, Jorgensen HL, Christensen J, Schwarz P, Heegaard AM, Lind B: A reverse J-shaped association of all-cause mortality with serum 25 hydroxyvitamin D in general practice: the CopD study. J Clin Endocrinol Metab 2012, 97:2644 2652

37. Holick MF, Binkley NC, Bischoff-Ferrari HA, Gordon CM, Hanley DA, Heaney $\mathrm{RP}$, Murad MH, Weaver CM: Guidelines for preventing and treating vitamin D deficiency and insufficiency revisited. J Clin Endocrinol Metab 2012, 97:1153 1158.

38. Vieth R, Bischoff-Ferrari H, Boucher BJ, Dawson-Hughes B, Garland CF, Heaney RP, Holick MF, Hollis BW, Lamberg-Allardt C, McGrath JJ, Norman AW, Scragg R, Whiting SJ, Willet WC, Zitterman A: The urgent need to recommend an intake of vitamin D that is effective. Am J Clin Nutr 2007 85:649 650.

39. Marshall TG: Vitamin D discovery outpaces FDA decision making. Bioessays 2008, 30:173 182

40. Zittermann A, Schleithoff SS, Frisch S, Gotting C, Kuhn J, Koertke H, Kleesiek K, Tenderich G, Koerfer R: Circulating calcitriol concentrations and total mortality. Clin Chem 2009, 55:1163 1170.

41. Venkatesh B, Davidson B, Robinson K, Pascoe R, Appleton C, Jones M: Do random estimations of vitamin D3 and parathyroid hormone reflect the 24-h profile in the critically ill? Intensive Care Med 2012, 38:177 179

42. Lee P: Vitamin D metabolism and deficiency in critical illness. Best Pract Res Clin Endocrinol Metab 2011, 25:769 781.

43. Roth HJ, Schmidt-Gayk H, Weber H, Niederau C: Accuracy and clinical implications of seven 25-hydroxyvitamin D methods compared with liquid chromatography-tandem mass spectrometry as a reference. Ann Clin Biochem 2008, 45:153 159

doi:10.1186/s13054-014-0660-4

Cite this article as: de Haan et al:: Vitamin D deficiency as a risk factor for infection, sepsis and mortality in the critically ill: systematic review and meta-analysis. Critical Care 2014 18:660. 